\title{
Body-force and mean-line models for the generation of axial compressor sub-idle characteristics
}

\author{
Mauro Righi ${ }^{1 *}$ Luis E. Ferrer-Vidal ${ }^{1}$, Vassilios Pachidis ${ }^{1}$ \\ ${ }^{1}$ Cranfield University, Cranfield, Bedfordshire, MK43 OAL, United Kingdom
}

\begin{abstract}
This paper describes the application of low-order models to the prediction of the steady performance of axial compressors at sub-idle conditions. An euler body-force method employing sub-idle performance correlations is developed and presented alongside a mean-line approach employing the same set of correlations. The low-order tools are used to generate the characteristic lines of the compressor in the locked-rotor and zero-torque windmilling conditions. The results are compared against steady-state operating points from 3D RANS CFD. The accuracy of the low-order tools in reproducing the results from high-fidelity CFD is analysed and the trade-off with the computational cost of each method is discussed. The low-order tools presented are shown to offer a fast alternative to traditional CFD which can be used to predict the performance in sub-idle conditions of a new compressor design during early development stages.
\end{abstract}

$\begin{array}{ll}\text { Nomenclature } \\ E_{0}, H & \text { Internal energy, Enthalpy }\left[\mathrm{J} / \mathrm{m}^{3}\right] \\ f & \text { Volumetric force }\left[\mathrm{N} / \mathrm{m}^{3}\right] \\ \bar{f} & \text { Body-force terms vector }[-] \\ I & \text { Shaft inertia }\left[\mathrm{kg} \cdot \mathrm{m}^{2}\right] \\ i & \text { Incidence angle }[\mathrm{deg}] \\ M & \text { Mach number }[-] \\ \dot{m}, \dot{m}^{\prime} & \text { Massflow }[\mathrm{kg} / \mathrm{s}], \text { Design point } \\ & \text { malised corrected massflow }[-] \\ P & \text { Pressure }[\mathrm{Pa}] \\ P R & \text { Pressure ratio }[-] \\ r & \text { Radius }[\mathrm{m}] \\ R e & \text { Reynolds number }[-] \\ \bar{S} & \text { Source terms vector }[-] \\ T & \text { Temperature }[\mathrm{T}] \\ t, d t & \text { Time, time step }[\mathrm{s}] \\ \bar{U} & \text { Conservative variables }[-] \\ u & \text { Flow velocity }[\mathrm{m} / \mathrm{s}] \\ x & \text { Axial position }[\mathrm{m}] \\ W_{E X} & \text { Work exchange }\left[\mathrm{W} / \mathrm{m}^{3}\right] \\ & \end{array}$

\section{Greek symbols}

$\beta \quad$ Angle in the streamline direction $[\mathrm{deg}]$

$\gamma \quad$ Stagger angle $[\mathrm{deg}]$

$\delta \quad$ Deviation angle $[\mathrm{deg}]$

$\theta \quad$ Circumferential position $[\mathrm{rad}]$

$\rho \quad$ Density $\left[\mathrm{kg} / \mathrm{m}^{3}\right]$

$\sigma \quad$ Solidity [-]

$\tau \quad$ Torque $[N \cdot m]$

$\tau^{\prime} \quad$ Corrected torque parameter $[N \cdot \mathrm{m} / \mathrm{Pa}]$

$\Omega, \Omega^{\prime}$ Rotational speed $[\mathrm{rad} / \mathrm{s}]$, Normalised rotational speed [-]

$\omega \quad$ Pressure loss coefficient [-]

\section{Subscripts}

$r, x, \theta$ Radial, axial, circumferential direction

METAL Direction of the metal camberline

$F L O W$ Direction of the flow

IN Blade row inlet conditions

OUT Blade row outlet conditions

$T \quad$ Total quantity

\footnotetext{
*Corresponding author

e-mail address:m.righi@cranfield.ac.uk
} 


\section{INTRODUCTION}

An aviation engine is exposed to the sub-idle regime on start-up or during windmill relight. While these events have historically not warranted a detailed performance evaluation, more stringent certification standards, customer requirements and the push for marginal benefits in fuel efficiency have highlighted the need for accurate sub-idle performance characterization ${ }^{(1)}$. Additionally, modern engines with increasing by-pass ratios put a strain on relight capability, while larger gearboxes and driven accessories also contribute to increased windmilling drag and reduced starting performance ${ }^{(2)}$. As the trend for higher by-pass ratios and geared configurations continues to increase, so too does the need for improved sub-idle performance, requiring improved prediction techniques.

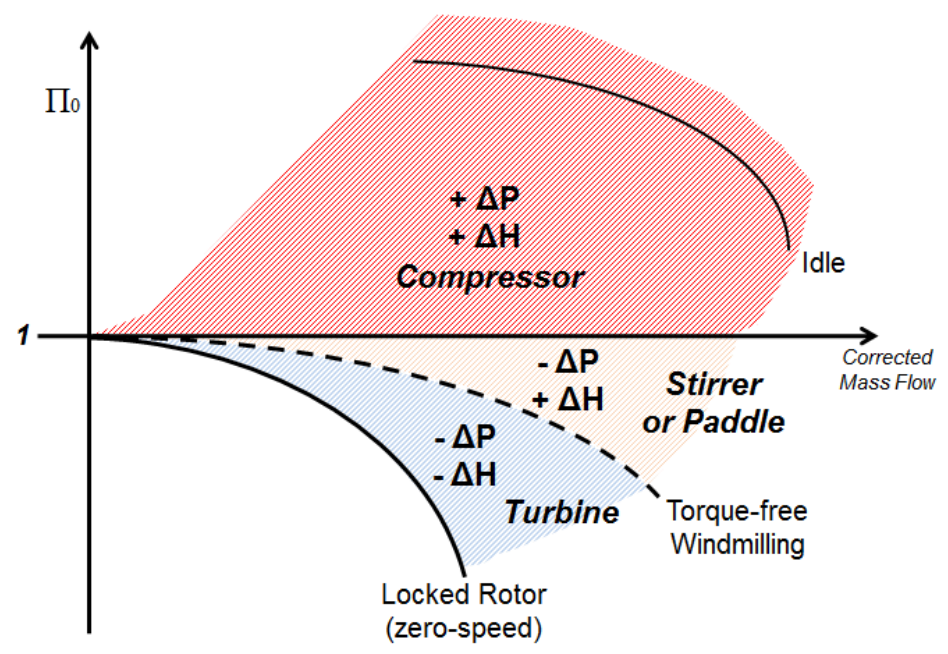

Figure 1: Example of sub-idle compressor map with different operating regimes.

The sub-idle portion of a map can be divided into three distinct regions depending on the sign of the work and total pressure changes, as in Figure 1. While any point with a pressure ratio above unity is considered inside the compressor operation region, the regions with a total pressure loss can be divided into stirrer and turbine modes depending on the sign of the work input. In the stirrer mode, there is a work addition to the flow along with a pressure loss, while work extraction and pressure loss define the turbine mode. A key element of the map is the boundary between these last two regions, which corresponds to the torque-free windmilling characteristic. At this torque-free windmilling condition, there is no net torque on the shaft and no net work done on the gas. In the absence of loads and frictional losses, the torque-free windmilling line could be reached by a compressor simply due to the incoming flow, and represents the maximum speed attainable by an unpowered compressor at a given massflow. In a real-life application, the presence of a turbine can result in steady state windmilling operation above the torquefree windmilling line. Conversely, frictional losses and work extraction would bring the operational point into the turbine region ${ }^{(3)}$. At the lower extreme of the map, the locked rotor line corresponds to zero speed operation, where flow simply passes through the compressor, incurring a pressure loss and imparting torque on the shaft. Due to the net enthalpy change $(\Delta H)$ becoming zero at the torque-free windmilling and locked rotor lines of an adiabatic compressor, performance parameters containing an enthalpy term in the denominator are not continuously defined throughout the sub-idle region. For this reason, the corrected torque parameter $\left(\tau_{p}\right)$ is used alongside the pressure ratio and corrected massflow to describe compressor performance in the sub-idle region ${ }^{(4)}$. This parameter is defined as the shaft torque divided by inlet total pressure ${ }^{(3)}$.

In order to accurately predict whole-engine performance using a zero-dimensional solver, maps are required for the different engine components. As data of performance at speeds lower than the idle conditions is scarce and not generally obtained from rig tests, a way to generate these maps needs to be devised. Several techniques have come about for the generation of sub-idle compressor maps using 
a variety of graphical ${ }^{(5)}$, and analytical methods ${ }^{(6)(7)}$. These are generally low-fidelity approximations that limit the accuracy of the generated performance data. A review of these methods can be found in Jones et al. ${ }^{(8)}$. Previous work at Cranfield University has looked at enhancing map generation by including interpolation from limited sub-idle data, such as locked rotor and windmilling characteristics ${ }^{(9)(10)}$. While these last methods have shown to result in viable maps, they highlight the need to accurately calculate the locked rotor and, especially, windmilling characteristics to further improve the reliability of the maps generated. The numerical scheme presented in Righi et al. ${ }^{(11)}$ has shown the capability to model compressor operation at extreme off-design cases, and as such is a strong candidate for application to the sub-idle case. This paper concerns itself with the adaptation of the low-order through-flow code presented in that work to the modelling of a modern multi-stage, high-speed high-pressure compressor in sub-idle conditions along with validation against high-fidelity 3D CFD. The significance of these simulation results is that they may be used as inputs to the map generation method presented in Ferrer-Vidal et al. ${ }^{(10)}$, yielding compressor maps of improved accuracy.

\section{LOW-ORDER MODELS}

\subsection{Euler Numerical Method}

The code ACRoSS (Axial Compressor Rotating Stall and Surge simulator) is a through-flow code developed at Cranfield University ${ }^{(11)}$. The code was originally created to handle compressor stall transients, where a $3 \mathrm{D}$ formulation is required for the proper simulation of stall cells. For the sub-idle modelling however, the flow is considered axisymmetric and a $2 \mathrm{D}$ formulation is used by setting the number of circumferential elements to one. The flow equations are solved transiently on a relatively coarse grid, as required to maintain acceptable computational cost. A structured mesh is generated based only on the annulus geometry and the input number of elements in the axial, radial and circumferential directions, with no need for detailed mesh generation. The compressor annulus is discretised as an empty duct and the blade rows are introduced using the body-force method. The equations solved are the unsteady, compressible, cylindrical Euler equations, written in matrix form as:

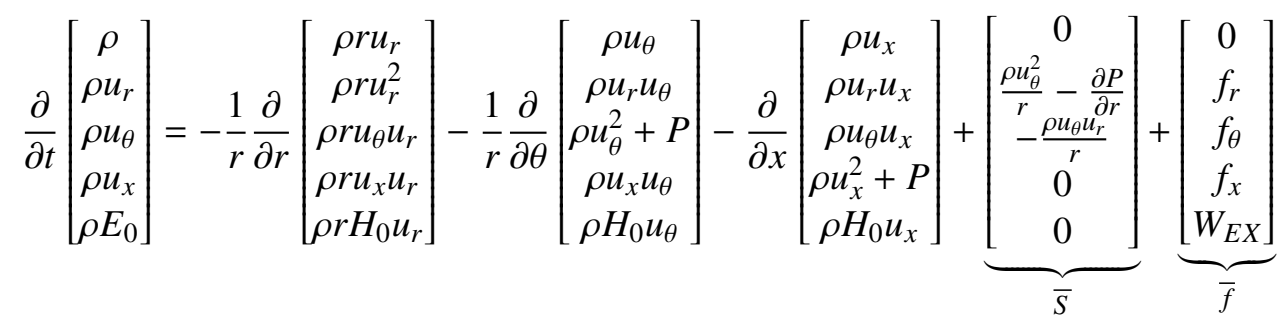

where $\bar{f}$ is the vector of the body-force terms and $\bar{S}$ is the source terms vector. The monotone, $1^{S T}$ order Godunov scheme is used for the solution of Eq. 1, the time-stepping is performed using an Euler forward scheme.

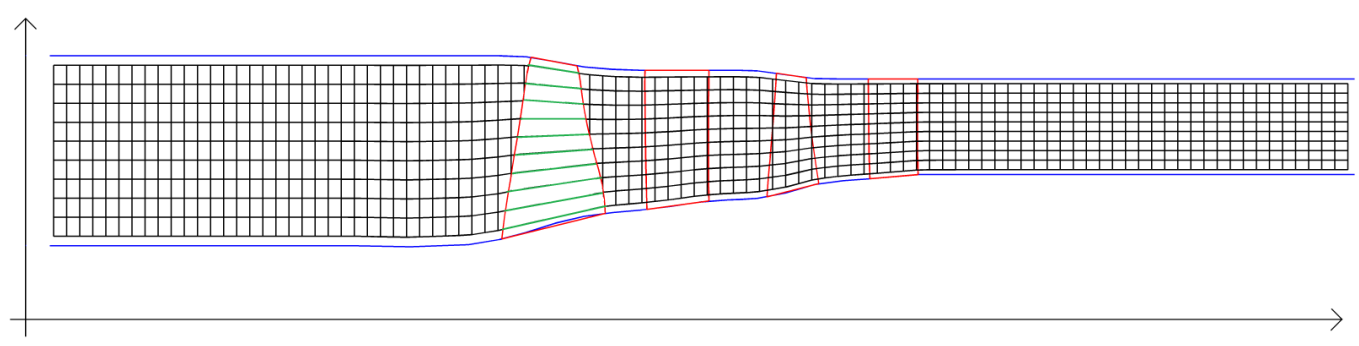

Figure 2: Example of the automatically generated grid. Highlighted in green are the pseudo-planes along which the body-forces are applied, created by connecting axially the volume centroids. 
The formulation used to calculate the body-forces is derived from that proposed in Longley ${ }^{(12)}$ and Brand $^{(13)}$. The forces are calculated along the pseudo-planes formed by the grid, as shown in Figure 2. The forces are then decomposed and applied onto the grid in the radial, circumferential, and axial directions, represented by $f_{r}, f_{\theta}, f_{x}$ in the source term of Eq. 1 . A work exchange term $\left(W_{E X}\right)$ is also included, which accounts for the work input by the rotors to the flow. A detailed explanation of this methodology is given in Righi et al. ${ }^{(11)}$.

An external algorithm is necessary to estimate at every iteration the performance of the blade row, expressed as a pressure loss coefficient $\omega$ and a deviation $\delta$, defined as:

$$
\omega=\frac{\Delta P_{T}}{0.5 \rho u^{2}} \quad \delta=\beta_{F L O W} \text { OUT }-\beta_{\text {METAL OUT }}
$$

These are estimated for every blade row and at every pseudo-plane, based on the blade geometry and the flow conditions at LE and TE.

A set of empirical correlations taken from literature ${ }^{(14)}$ and a set developed by Rolls-Royce plc. are implemented in the code to model the performance of the blade during normal operations.

Neither of these sets of correlations is well suited to model separated blade rows, and the performance in such conditions is extrapolated from the normal operation. When separation occurs close to surge margin, it quickly triggers a compressor stall and an accurate prediction of $\omega$ and $\delta$ is not necessary. However in case of separation due to highly negative incidence angle $i$, as occurs during sub-idle conditions, a better prediction is necessary to model the steady, separated flow. In a previous effort, three low-order models for separated passages at negative incidence have been tested to model a small multi-stage compressor in sub-idle conditions and the results have been compared to experimental data. A set of correlations created by Ferrer-Vidal et al., presented in ${ }^{(15)}$, was found to be the model with the best accuracy; the results are reported in section 4.2.

These correlations are here implemented in ACRoSS and used only for negative incidence $i<0^{\circ}$, yielding loss and deviation as a function of cascade geometry and inlet conditions:

$$
(\omega, \delta)=f\left(\gamma, \sigma, i, M_{I N}\right)
$$

This new set of correlations is 'blended' to the standard set close to $i=0^{\circ}$ to avoid sudden jumps in performance.

The body-force method imposes the turning and pressure loss on the flow as predicted by the empirical correlations. The body-forces also ensure that the flow direction at the TE matches the value predicted by the deviation correlation. The pressure loss $\Delta P_{T}$ is redistributed in the grid elements inside of the blade row and introduced by mean of a force aligned to the flow. This implies that all of the turning and the pressure loss occurs inside of the blade row and the next blade row will observe a uniform inlet flow.

While this method offers an appropriate representation for unstalled conditions, when flow stalls and separates the physical behaviour can be very different. In the case of a separated passage, a large change in flow direction occurs during mixing downstream of the blade, with the resulting outflow angle being potentially very different from that observed at TE. Similarly, the separated flow remains mostly isentropic inside of the blade passage and the pressure loss occurs mainly during the mixing. In a real compressor, the rows are close enough that typically only part of the mixing will occur between the blades, therefore the flow is not uniform at the next row LE.

By introducing the sub-idle model in the low-order tool we are then imposing that, even when a passage separates, the uniform fully-mixed conditions (output of the model) are reached before the next blade LE; the authors refer to this as the fully-mixed wake assumption. Figure 3 shows the model of a separated passage blade on which the correlations are based and how it is represented by the body-force model.

The assumption introduced has two important implications:

- the interaction of the next blade row with the mixing of the wakes is ignored. 


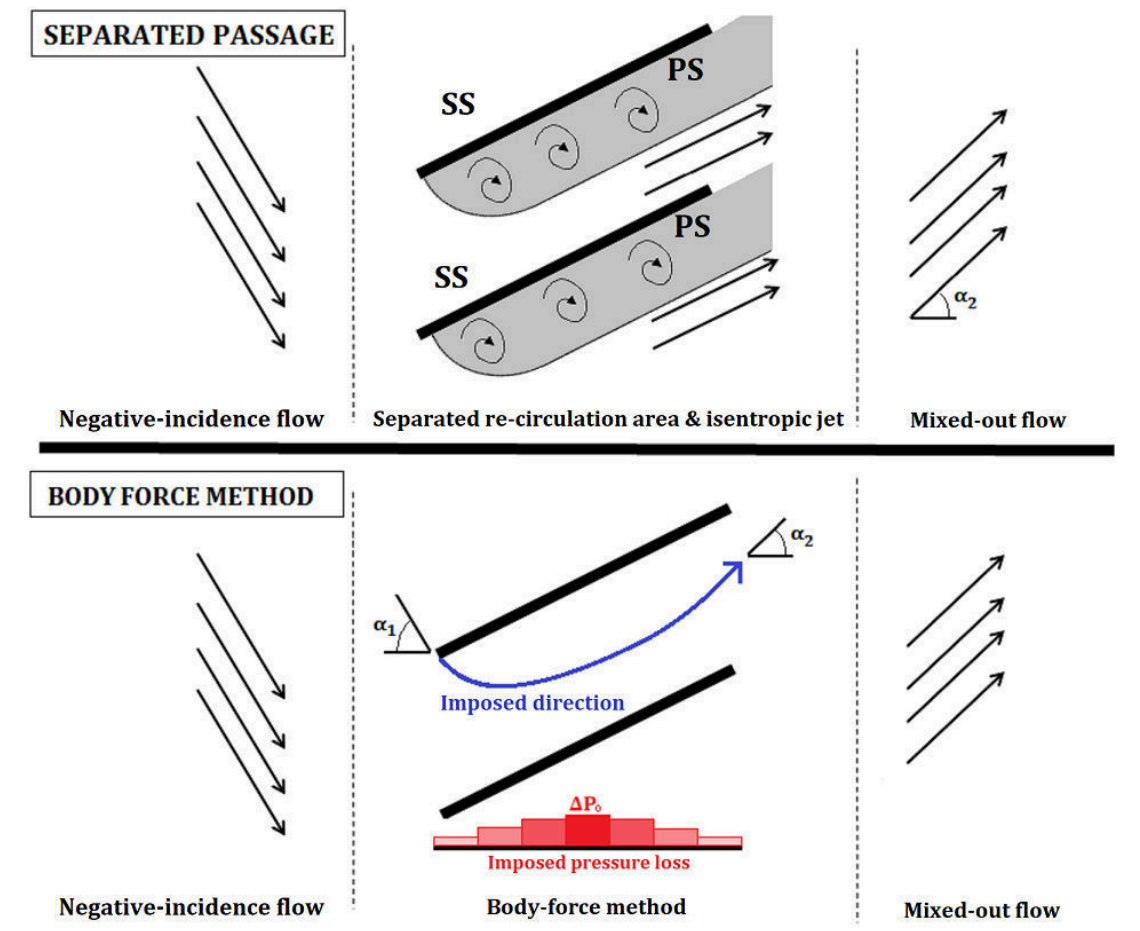

Figure 3: Model of a separated blade passage at high negative incidence and its implementation with the body-force method along one of the pseudo-planes at a specific span position.

- the performance of a blade row is estimated using as inlet conditions the uniform representation of the flow, and not the real separated flow.

As the flow is expected to be largely separated at the high negative incidences which occur in sub-idle conditions, the validity of this assumptions needs to be independently investigated.

To model the locked rotor case, the shaft RPM is set to zero. For the windmilling case, the torque on the rotors is calculated at every iteration and a simple balance equation is used to alter the rotational speed as shown in Eq. 4. The rotational speed changes until the torque matches the target value $\tau_{\text {target }}$, set to zero for the torque-free windmilling case. For the windmilling case, ACRoSS is employed in a pseudo-transient approach, so the shaft inertia $I$ is set to a very low value to accelerate convergence.

$$
\Omega^{t+1}=\Omega^{t}+\frac{\sum \tau+\tau_{\text {target }}}{I} \cdot d t
$$

Non-reflecting boundary conditions are applied at the inlet and outlet of the model ${ }^{(16)}$; total quantities are imposed at flow inlet and static pressure is imposed at the outlet. To generate the characteristics the outlet static pressure is lowered incrementally to simulate throttling.

\subsection{Mean line approach}

The mean line tool employs the well-known mean line, or pitch line, approach to solve the velocity triangles blade-by-blade from knowledge of the compressor mean line geometry. Such an approach requires knowledge of the blade deviation angles and loss coefficients to calculate the blade outlet conditions through the compressor. The same negative incidence loss and deflection model used for the Euler body-force method has been used here ${ }^{(15)}$. Like in the Euler method, the mean-line approach's monodimensional implementation necessarily implies fully-mixed wakes by assuming all losses have been realized by the time the flow reaches the subsequent blade row. Continuity is conserved through the solution of the axial velocity at the entry to the blade passage while momentum conservation is also established through the solution of the axial pressure distribution. Changes in the pitch line radius and 
flow path area are taken into account through conservation of angular momentum. The calculation is however one-dimensional as only the pitch line geometry is considered. The mean line approach is an established method and no further details are given here. Good overviews of the method may be found in $^{(17)}$ and $^{(18)}$.

A point to note regarding the mean line approach for the sub-idle regimes is the selection of the mean radius. In sub-idle conditions the span-wise work distribution may vary drastically along the span. This is particularly true for single stage fans, where part of the fan expands the flow while the other compresses it $^{(19)}$. In such a case, the selection of a single radial location to characterize performance can yield misleading results. For multi-stage machines of high hub-to-tip ratio, this change in operation occurs primarily with axial rather than radial location. Typically the front stages compress the flow, the rear stages expand it and an intermediate blade row acts as the switch-over point between the regimes; this is observed in the case analysed and presented in Section 4.3. The selection of a radius to characterize performance in multi-stage core compressors is therefore not as critical as in fans. In this work, the mean radius used for analysis is just the mean geometric radius between hub and shroud.

\section{RANS NUMERICAL METHODS}

The compressors studied have been modelled using 3D RANS CFD as a verification of the low-order approach. 2D RANS CFD cascade models have also been used to independently investigate the adequacy of the fully-mixed wake assumption.

\subsection{D Compressor Models}

The 3D CFD models are generated from geometry provided by Rolls-Royce plc. The geometry is discretised with a structured mesh generated using the ANSYS ${ }^{\circledR}$ Turbogrid $^{T M}$ software. The models consists of the clean blade geometry with no bleeds or leaks taken into account. In all cases, a wallmodelled mesh is used with $y+=\sim 30$. The mesh size is $5 \sim 6 \cdot 10^{5}$ elements per blade passage. With the sole goal of obtaining pressure ratio and torque values, a mesh sensitivity study was performed on a single stage simulation at locked rotor conditions. The error between the employed grid and the finest considered (at $8 \cdot 10^{6}$ elements per passage) was negligible for pressure ratio and $0.7 \%$ for torque. Simulations are run with the ANSYS ${ }^{\circledR}$ CFX $^{\circledR}$ solver, Release 18.2, using a $k-\omega$ SST turbulence model and employing the automatic wall-function treatment. Boundary conditions consist of inlet total pressure and temperature and massflow outlet. The inlet conditions used are $1 \mathrm{~atm}, 288.15 \mathrm{~K}$. No-slip walls are used on blade and hub surfaces. The casing over rotor tips is a stationary no-slip wall in the absolute reference frame (counter-rotating wall). Tip gaps are modelled for rotor blades as $1 \%$ of the span and discretised with 15 elements. The multi-stage compressors have been modelled using mixing planes between each blade row such that the flow-field is averaged before passing onto the next blade row. This allows a single passage model to be used. While the large separated wakes present at locked rotor conditions would span several passages, foregoing the use of mixing planes requires domain pitches to be matched which, in the case of a modern multi-stage compressor, entails the modelling of large annular sectors, straining computational resources. Since the goal of this investigation is to compare 3D NavierStokes CFD results against low-order models which also employ the blade row mixing assumption, this limitation in the numerical model is deemed acceptable for the analysis. The fully-mixed wake assumption is discussed in detail later within this paper. The known limitations of steady RANS CFD to accurately capture the physics of separated flows needs to be considered when attempting to apply these methods to sub-idle operation. However, as the current application seeks to develop methods that predict bulk performance parameters, the emphasis must be put on using RANS CFD as the highestfidelity through flow tool available, used solely to calculate characteristics. A previous study ${ }^{(20)}$ already compared CFD results against experimental data with a favourable outcome, as can be seen in Figure 4.

Reduced-order models that are at least able to match the performance of RANS CFD while offering significant reductions in overhead and computational requirements are important to engineers in need of 

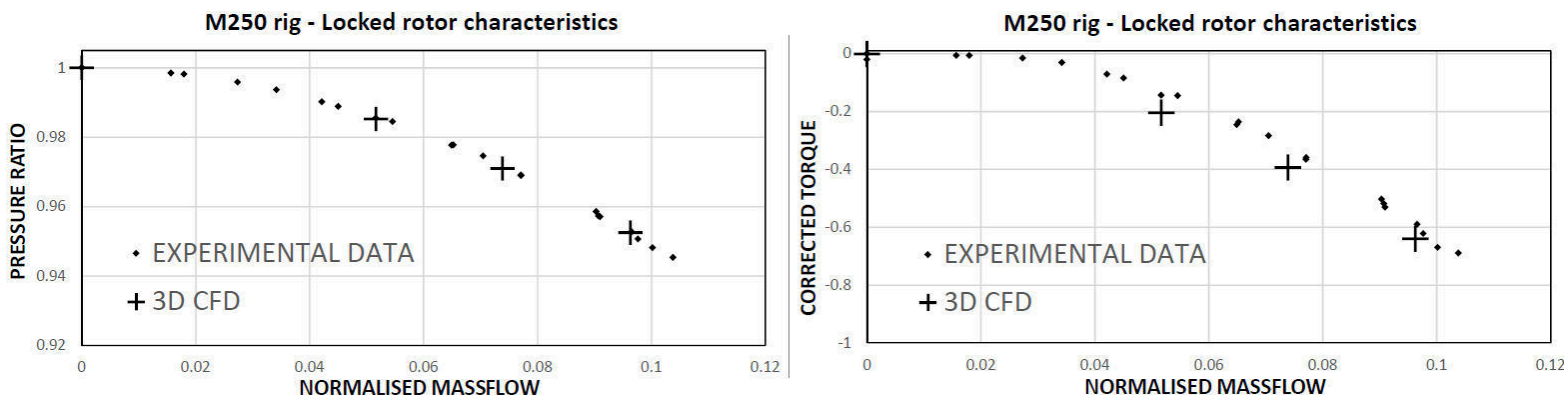

Figure 4: Locked rotor pressure ratio and corrected torque characteristics as measured in experiment and calculated in CFD. Adapted from ${ }^{(20)}$.

fast and reliable performance data.

\subsection{D Cascade Study}

The validity of the fully-mixed wake assumption is assessed using a 2D CFD RANS model consisting of two blade rows subjected to a high negative incidence flow. The model is solved using the ANSYS ${ }^{\circledR}$ Fluent ${ }^{\circledR}$ solver, Release 18.2. The CFD implementation is purely 2D (no geometry or mesh extrusion) resulting in unity Axial-Velocity Density Ratio. Six studies are performed with different sets of blade rows. For each study we distinguish a case a) with the rows at short distance ( 1 chord), and a case b) with rows far apart ( $\sim 6$ chords) such that the separation wakes from the first row are fully mixed-out before reaching the second; an example is presented in Figure 5.

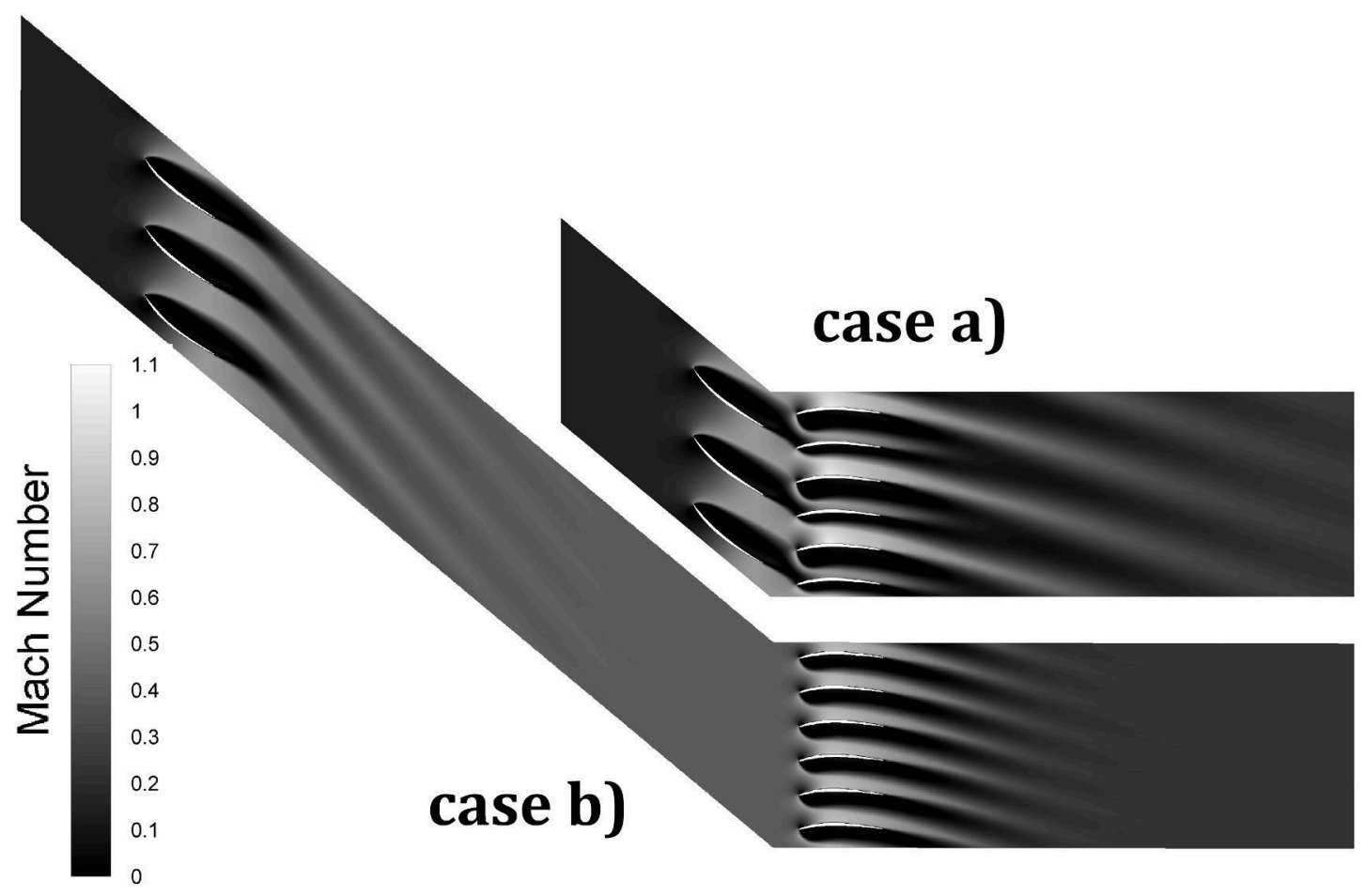

Figure 5: Example of CFD simulations using ANSYS ${ }^{\circledR}$ Fluent ${ }^{\circledR}$ software of separated blade rows with normal inter-blade distance, case a), and large distance, case b).

The first blade row has constant stagger and solidity but two different settings of inlet angle, so that two magnitudes of wakes can be studied. The solidity of the downstream blades changes in every study, 
so that the interaction of wakes and passages changes every time. The details of the studies are reported in Table 1.

Table 1: Set-up of the CFD studies used to assess the fully-mixed wake assumption

\begin{tabular}{|ll|r|r|r|r|r|r|}
\hline & & Study 1 & Study 2 & Study 3 & Study 4 & Study 5 & Study 6 \\
\hline Inlet angle & {$[\mathrm{deg}]$} & $45^{\circ}$ & $45^{\circ}$ & $45^{\circ}$ & $0^{\circ}$ & $0^{\circ}$ & $0^{\circ}$ \\
\hline Row 1 stagger & {$[\mathrm{deg}]$} & $-45^{\circ}$ & $-45^{\circ}$ & $-45^{\circ}$ & $-45^{\circ}$ & $-45^{\circ}$ & $-45^{\circ}$ \\
\hline Row 1 solidity & {$[-]$} & 1.206 & 1.206 & 1.206 & 1.206 & 1.206 & 1.206 \\
\hline Row 2 stagger & {$[\mathrm{deg}]$} & $55^{\circ}$ & $55^{\circ}$ & $55^{\circ}$ & $0^{\circ}$ & $0^{\circ}$ & $0^{\circ}$ \\
\hline Row 2 solidity & {$[-]$} & 0.804 & 1.608 & 2.411 & 0.804 & 1.206 & 2.411 \\
\hline
\end{tabular}

All blade rows consist of the same mid-stage rotor profile which was used in the CFD campaign from which the negative incidence loss and deviation models were developed ${ }^{(15)}$. All simulations are run with stationary blade rows. The equations solved are the compressible RANS, the turbulence is modelled using the k- $\omega$ SST model. Total pressure and temperature are prescribed at inlet, static pressure at outlet is set to obtain the specified target massflow. For every study and case the mesh was checked for grid convergence. The finest grid used on the largest domain, case b) study 3 , has $\sim 1.25 \cdot 10^{6}$ elements.

\section{RESULTS AND DISCUSSION}

The fully-mixed wake assumption is first considered, followed by a discussion of the application of the low order models to two specific multi-stage compressor geometries.

\subsection{Fully-mixed Wake Assumption}

Using the 2D cascade model developed, pressure loss and deviation values obtained with different levels of inter-blade mixing can be compared. These are estimated using the flow at domain inlet and domain outlet. The domain extends several chords downstream of the second blade row. In all studies the wakes mixes fully within the domain and the flow is uniform by the time it reaches the outlet where it is measured. The results are presented in Figure 6. The pressure loss is reported using an overall pressure loss coefficient, defined as the total pressure difference between domain inlet and outlet normalised over the dynamic head at domain inlet. The deviation angle reported is calculated on the last blade row, using the mixed-out flow direction at domain outlet. The Reynolds number in the study varies from $2 \cdot 10^{4}$ at low Mach number to $2 \cdot 10^{5}$ at maximum Mach number.

From the results it can be observed that in every study the difference in the deviation angle is less than $2.5^{\circ}$ between the two cases. The discrepancy in pressure loss coefficient is up to $\sim 8 \%$. It should be noted that, as the discrepancy reported is in pressure loss and not pressure ratio, it does not multiply along the blade rows, and in a multi-stage compressor the cumulative error in pressure loss coefficient would not be higher than the maximum error of the individual rows.

Based on these results, the fully-mixed assumption is considered accurate enough for the fast creation of windmilling and locked rotor characteristics.

\subsection{Six-stage turbo-shaft compressor}

In this study, a six-stage turbo-shaft compressor is modelled using the mean-line tool and the code ACRoSS in windmilling and locked rotor conditions. The results are compared to 3D RANS CFD and experimental data from ${ }^{(20)}$.

For pressure ratio in the locked rotor case (Figure 7), all models match well with discrepancies from experimental data well below $1 \%$. For the torque however (Figure 8), the matching is more moderate. The maximum discrepancies in torque reach $20 \%$ however such a large relative discrepancy is simply due to the low torque values considered. The maximum absolute torque discrepancy is $0.15 \mathrm{~N} \cdot \mathrm{m}$. 

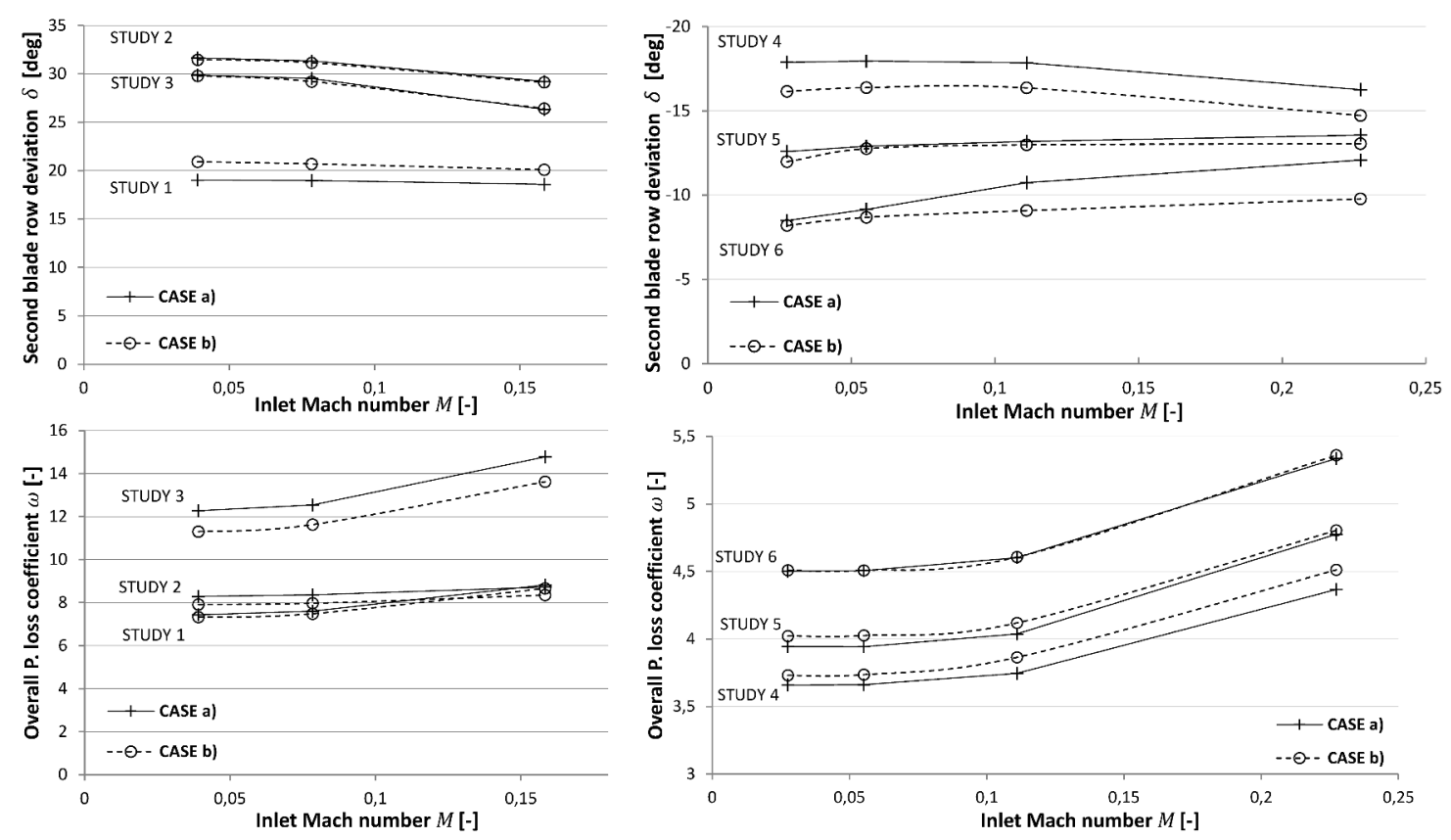

Figure 6: Results from the 2D cascade CFD simulation. Overall pressure loss coefficient and deviation angle are compared from six different set-ups with normal inter-blade distance, case a), and large distance, case b).

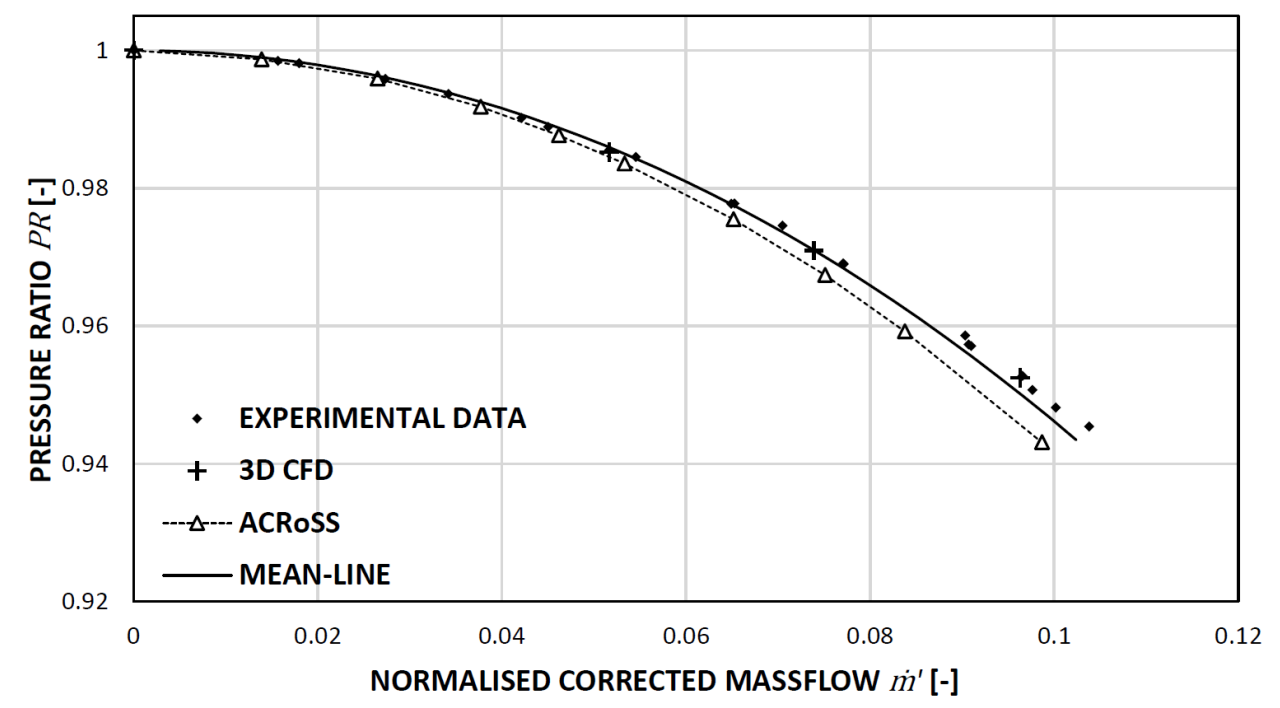

Figure 7: Comparison of the six-stage turbo-shaft locked rotor pressure ratio characteristics calculated using 3D CFD and the two low-order models, with comparison to experimental data from ${ }^{(20)}$.

All models including CFD appear to under-predict pressure losses in the torque-free windmilling case as seen in Figure 9. The two low-order models match experiment more accurately in this case, with the maximum discrepancy between the mean-line method and experiment being $0.3 \%$.

For torque-free windmilling, the net shaft torque is taken as zero and the value worth comparing is the predicted RPM obtained from the low-order models. For the RANS solutions, an iterative approach was taken to vary the outlet boundary condition until torque was zeroed. Figure 10 shows the resulting level of matching for the different models, with the low-order approaches again out-performing the RANS results in this specific case with a discrepancy in the predicted slope of only $1.3 \%$ for ACRoSS compared to $3.1 \%$ for the RANS CFD. The improved performance of the low-order models can partly 


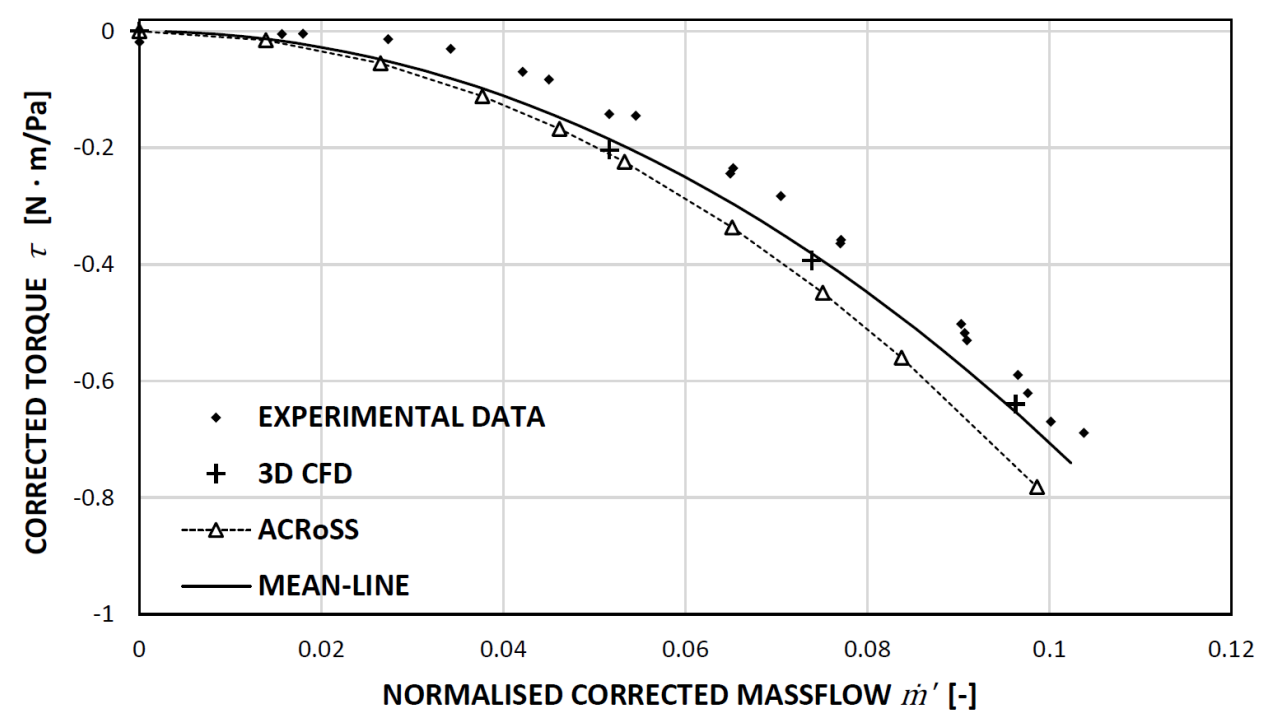

Figure 8: Comparison of the six-stage turbo-shaft locked rotor torque characteristics calculated using 3D CFD and the two low-order models, with comparison to experimental data from ${ }^{(20)}$.

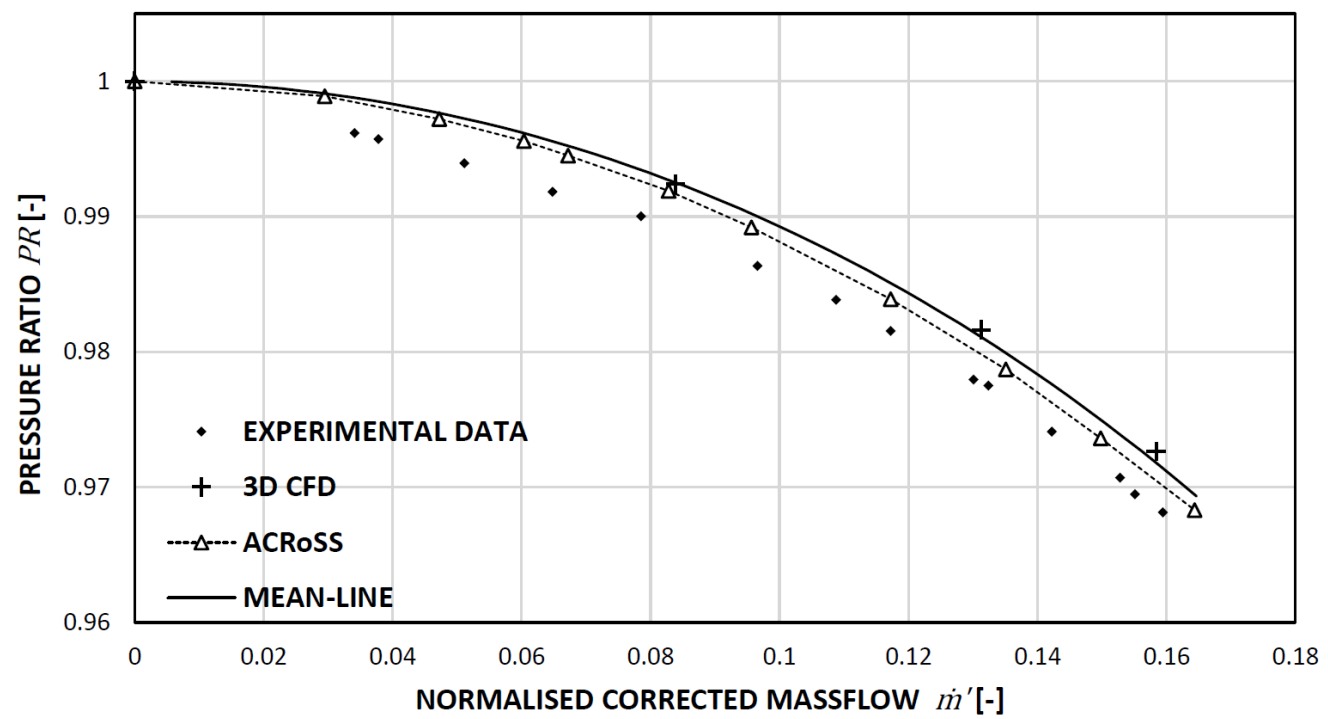

Figure 9: Comparison of the six-stage turbo-shaft torque-free windmilling pressure ratio characteristics calculated using 3D CFD and the two low-order models, with comparison to experimental data from ${ }^{(20)}$.

be attributed to the iterative approach in reaching a zero-torque condition. Iterative variation of the boundary conditions with RANS CFD can only reach torque levels below $1 N \cdot m$ before computational time becomes excessive, while two orders of magnitude tighter convergence can be reached with the two low-order models.

\subsection{Six-stage high pressure compressor}

The previous geometry was chosen due to the availability of experimental data, however it is not representative of modern large civil engines. Additionally, the previous test case did not include data at very high massflows, so the applicability of the methods to conditions near choke could not readily be evaluated. In order to apply the methods to a more relevant case, a six-stage high-speed high pressure compressor (HPC) representative of modern aero-engine is also investigated and calculations from the mean-line and ACRoSS models are compared to the 3D RANS CFD. As no experimental data is avail- 


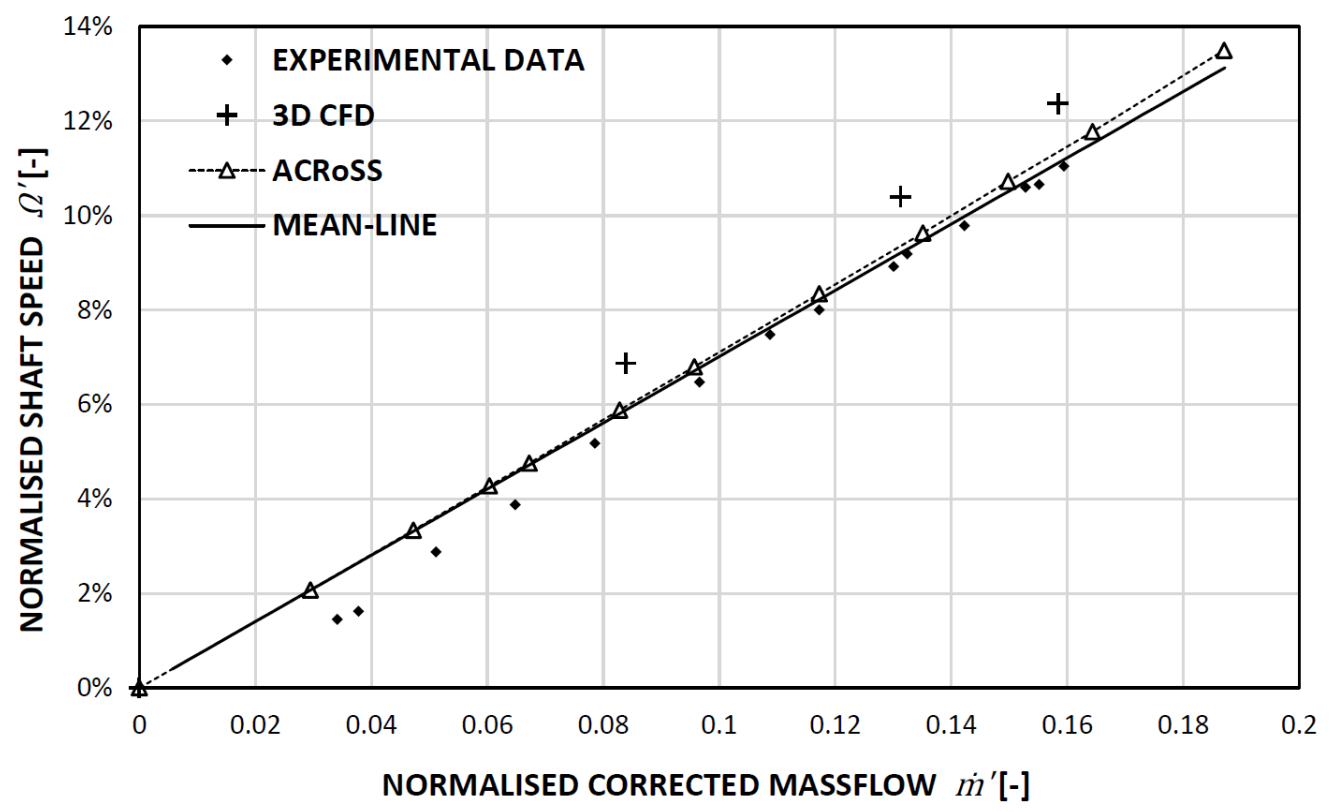

Figure 10: Comparison of the six-stage turbo-shaft torque-free windmilling speeds calculated using 3D CFD and the two low-order models, with comparison to experimental data from ${ }^{(20)}$.

able for this compressor, RANS CFD is taken as the reference, considered here as the conceptually highest fidelity tool available.

The ACRoSS model has a grid of 920 axial $\times 12$ radial elements, the annulus duct is extended straight in front and behind the blade rows by $\sim 1$ front stage blade chord. This very short domain speeds up the calculation and is acceptable in this application as no mixing is expected in front of or behind the compressor. The results of some selected cases have been also reproduced with longer inlet and outlet ducts, to ensure that no error is introduced by the shortened domain. A convergence study was also performed to check that grid independence is reached.

The results for the locked rotor conditions are presented in Figures. 11-12. The characteristics are presented using the corrected massflow normalised over the design value, $\dot{m}^{\prime}$, total-to-total pressure ratio, $P R$, normalised shaft speed, $\Omega^{\prime}$, and the corrected torque parameter, $\tau^{\prime}$, defined as the torque on the shaft divided by the inlet total pressure. As the present study focuses on sub-idle conditions, these are expected to be much lower than the design value (set at $100 \%$ speed). The characteristic created using ACRoSS extends until choking conditions are reached at $\dot{m}^{\prime}=0.15$. The choking occurs as the flow reaches sonic conditions inside of a blade. This is not accurately modelled by the body-force method, because the blade thickness and the separation in the passages are not taken into account by the Euler solver. However as the flow approaches choking conditions, the rapid increase of the pressure loss coefficient causes the characteristic to steepen and choking massflow is quickly reached.

The mean-line analysis matches very closely the data from CFD along the whole characteristic. The code ACRoSS has better results over the mean-line tool, as the latter over-predicts the pressure losses close to choking conditions.

The comparison of the results from windmilling conditions are presented in Figures. 13-14. The windmilling signature is reported using the corrected rotational speed normalised by the design value $\Omega^{\prime}$. In the current study all results are obtained through numerical models in which friction is not included, as a result the data in Figure 14 aligns with the origin of the chart.

Both the low-order tools under-predict the pressure losses with respect to the CFD results; as observed in the locked rotor simulation, the characteristics from the low-order tools diverge close to choking conditions with the mean-line tool predicting higher pressure losses. Despite the large difference in the pressure characteristics, the signature line is closely reproduced and the discrepancy from CFD data in the line slope is $7.5 \%$ for ACRoSS and $12 \%$ for the mean-line tool. 


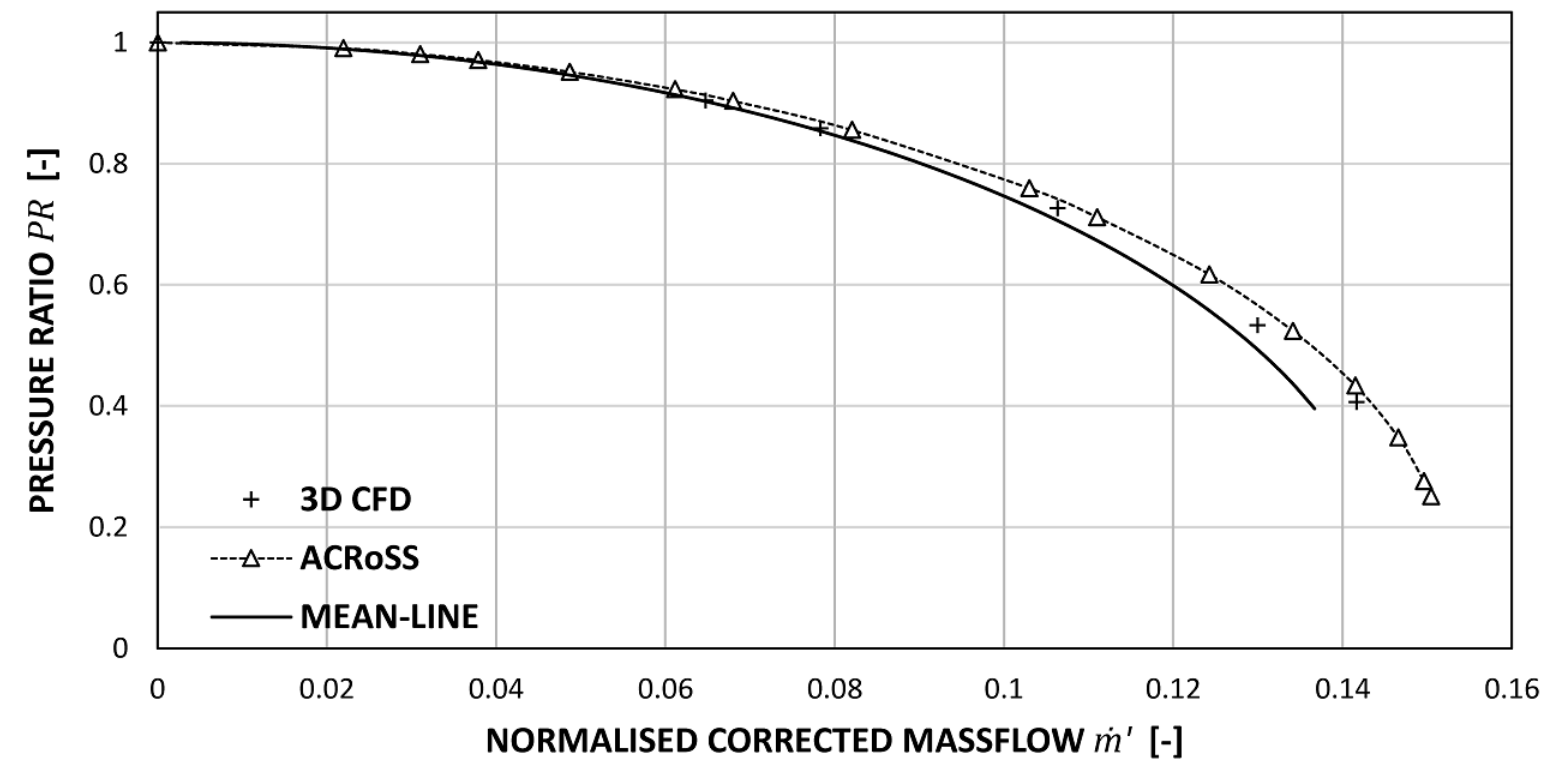

Figure 11: Comparison of the six-stage HPC locked rotor pressure characteristic predictions using highfidelity 3D CFD and the two low-order models

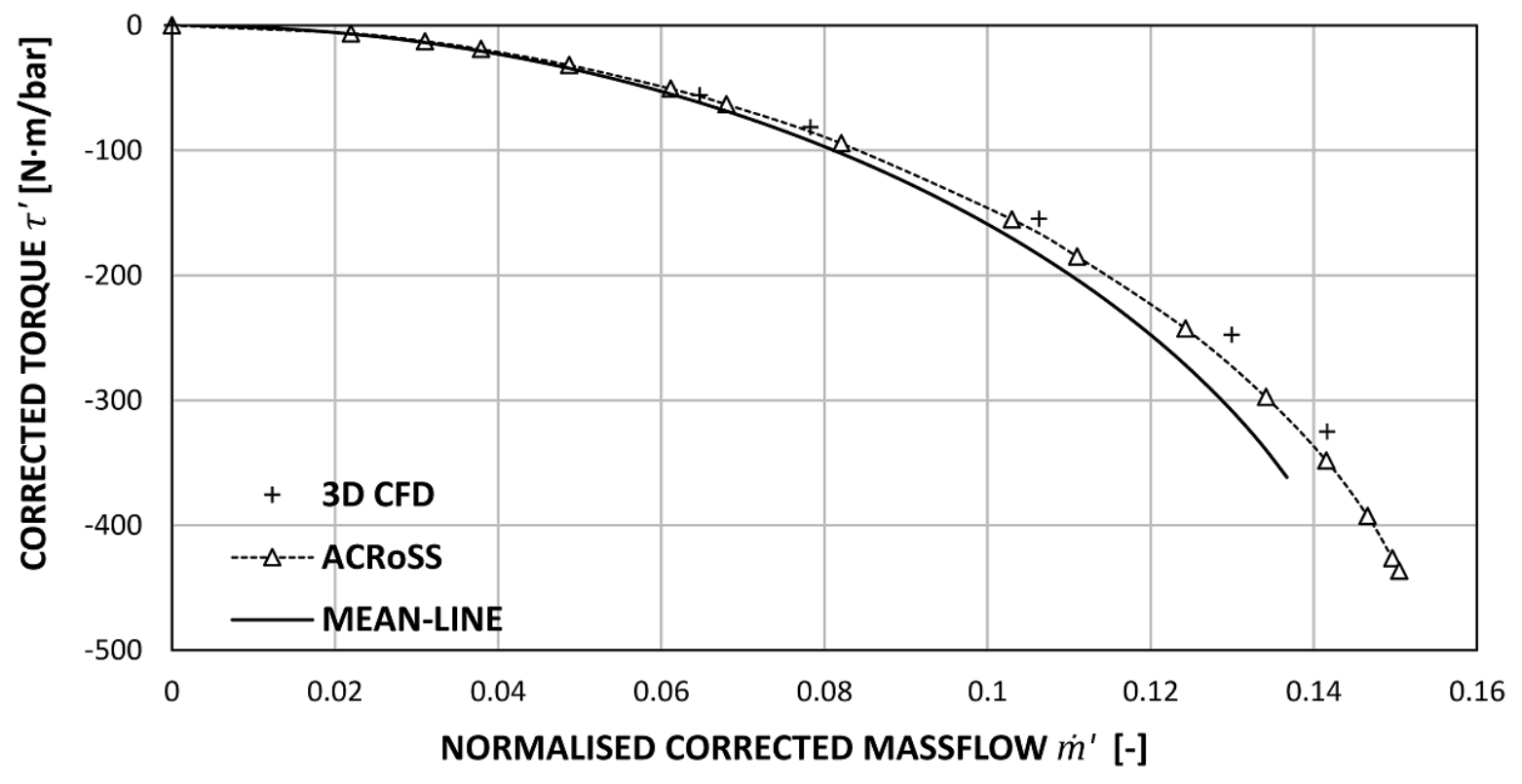

Figure 12: Comparison of the six-stage HPC locked rotor torque characteristic predictions using highfidelity 3D CFD and the two low-order models

Because of its span-wise resolution, the code ACRoSS can analyse the different torque contributions that blade rows have at different radial positions during windmilling, potentially identifying blades which act both as a compressor and as a turbine. However, the results from ACRoSS show that, for this multistage high hub-to-tip ratio machine, the radial distribution of torque is mostly uniform as shown in Figure 15, with only some small variations seen at lower speeds. These results justify the use of the mean geometric radius as reference radius in the mean-line code for this type of compressor (i.e. core multi-stage compressors of high hub-to-tip ratio). As previously described by Righi et al. ${ }^{(20)}$, the axial distribution of torque remains mostly constant at different speeds in windmilling conditions.

By analysing the flow-field it was observed that at rotor 1 hub (and, at higher speed, also rotor 2) the blade is highly loaded, resulting in a stall with positive incidence being predicted by ACRoSS. This 


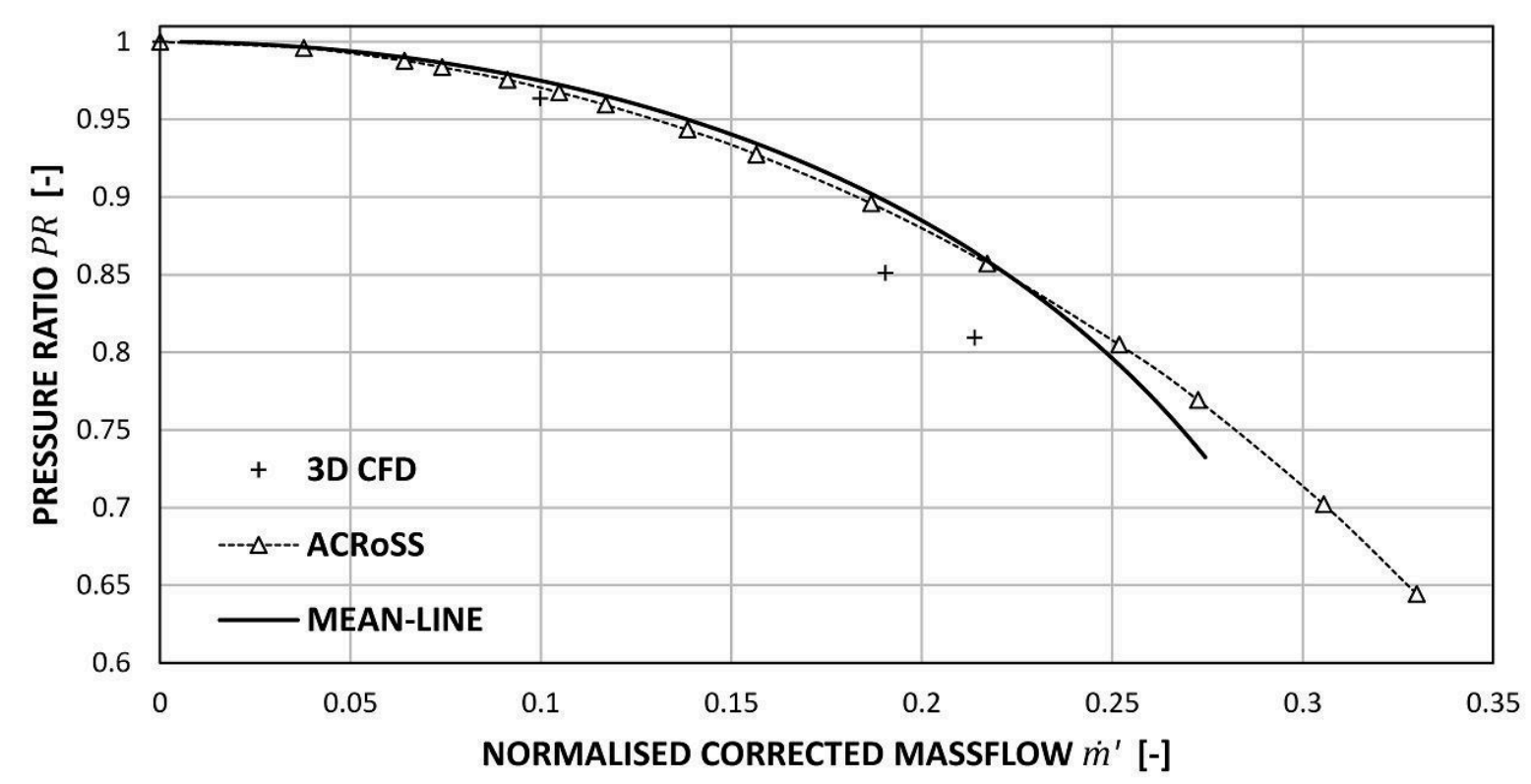

Figure 13: Comparison of the six-stage HPC windmilling pressure characteristic predictions using highfidelity 3D CFD and the two low-order models

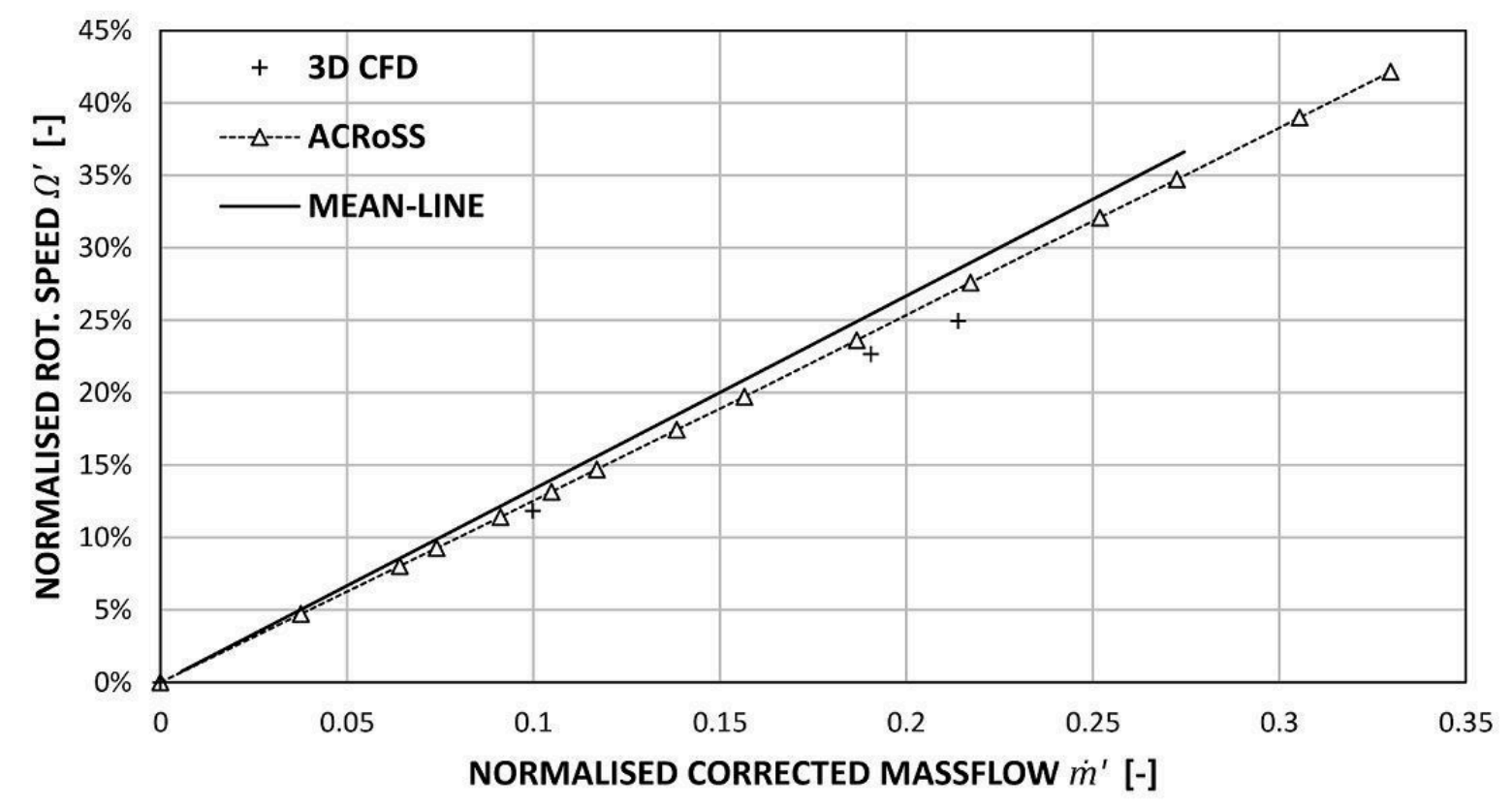

Figure 14: Comparison of the six-stage HPC windmilling signature line predictions using high-fidelity 3D CFD and the two low-order models

yields a large deviation and reduced mass-flow and torque locally at the rotor 1 hub, as seen in Figure 15. Because of the rotor mismatching, the stators in the front stage remain at a high negative incidence angle at the tip. This causes the flow to separate, causing a local increase in deviation. Away from these stalled areas, deviation and pressure loss remain mostly constant or linear in the span-wise direction in all blade rows. The alignment of the characteristics from ACRoSS and the mean-line code indicates that the locally stalled areas have a very limited effect on the overall performance. Radial redistribution of the flow is found to be negligible for these simulations. At all speeds, the flow in the meridional plane is misaligned from the pseudo-planes (and in general from the grid) by less than $5^{\circ}$ throughout. 


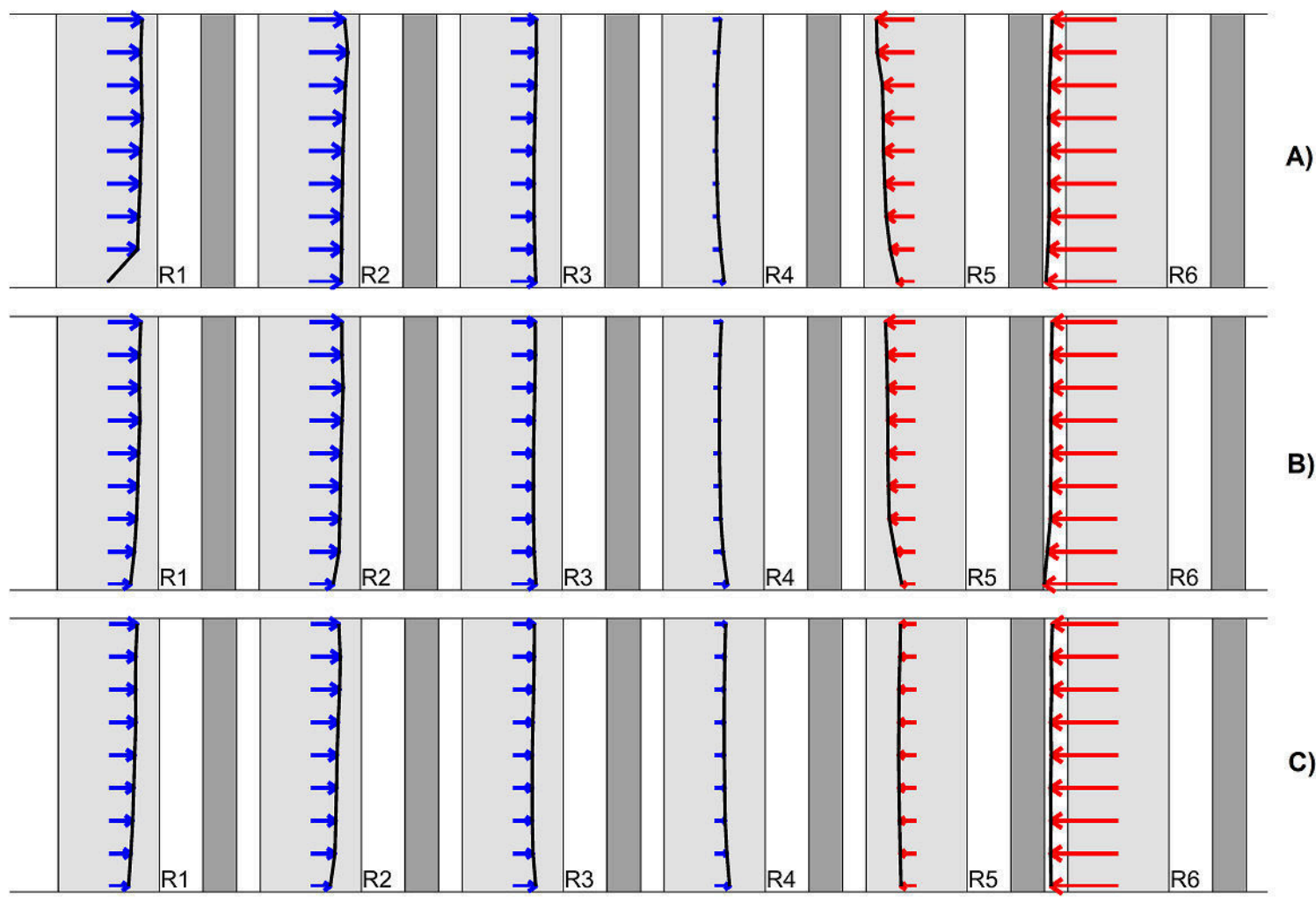

Figure 15: Rotor torque distribution in windmilling conditions at different speeds, A) $5 \% \Omega^{\prime}$, B) $19 \%$ $\Omega^{\prime}$, C) $32 \% \Omega^{\prime}$. Values not in scale across speeds. Blade rows acting as compressors are presented in blue and rows acting as turbines are in red.

\subsection{Computational cost}

The accuracy in the prediction of the sub-idle characteristics must be considered with the associated computational cost to assess the trade-off. In Table 2 the computational times required to model a single operating point and a characteristic are reported. Each code has been run using the computational resources which would typically be expected. The mean-line tool and ACRoSS have been run on a single quad-core workstation; ACRoSS is a parallel code and only one instance of the program is run at a time, requiring all the cores. The 3D CFD model has been run in parallel on a HPC facility, using 64 CPU's distributed across 4 four nodes with MPI and infiniband interconnect.

Table 2: Computational cost of the different models considered

\begin{tabular}{|l|c|c|}
\hline Model & \multicolumn{2}{|c|}{ Execution Wall Time } \\
& Single point & Characteristic \\
\hline 3D RANS CFD & 6 hours on 64 CPU's & 1 Day on 64 CPU's \\
2D Euler Body-force (ACRoSS 2D) & $\sim 5$ mins & $1 \mathrm{hr}$ \\
1D Mean-line & $<1 \mathrm{~s}$ & $\sim 1 \mathrm{~s}$ \\
\hline
\end{tabular}

Based on the computational costs the different methods seem to be appropriate for different applications:

- The mean-line method gives the least knowledge of the flow-field and has the most discrepancy from RANS CFD near the choke, however it is the only method fast enough to be automated for creation of characteristics or optimization.

- The code ACRoSS offers a better resolution and accuracy than the mean-line method, as well as 
adding the resolution in the span direction. However, this code requires more computational time and more user time to set-up and post-process the simulations and create a characteristic.

- High fidelity CFD has the highest fidelity and best resolution of the flow-field, especially as the entire blade passage and tip gaps are modelled. However, even for the simplified models used here, a large computational power is required to create a single operating point. Coupled to geometry generation, meshing and post-processing requirements, such an approach does not lend itself for use in compressor performance prediction during the design process. Furthermore, if the mixing plane approach were dropped in an effort to increase fidelity, even more computational power would be required due to the requirement for multi-passage simulation. This method is then more appropriate to analyse a single operating condition of particular interest, rather than creating characteristics.

The locked rotor and windmilling characteristics created with the low-order tools can be used to extrapolate the compressor map from the idle speed-line (known experimentally) down to 0 RPM. This method, described by Ferrer-Vidal et al. ${ }^{(10)}$, when coupled with the mean-line tool can create the whole sub-idle portion of the compressor map in few seconds.

The code ACRoSS can be used to simulate spool cranking. However during cranking the compressor can in some conditions develop a rotating stall, which would not be correctly modelled unless a full annulus simulation is employed. In that case a much longer computational time would be necessary, $20 \mathrm{hrs}$ for a single operating point. A 3D CFD model would not be able to model rotating stall either, unless the full annulus is modelled dramatically increasing the computational cost compared to the single passage simulation here presented.

\section{CONCLUSIONS}

Two low-order tools, a mean-line code and the through-flow code ACRoSS, are presented as an alternative to high-fidelity CFD to predict the sub-idle performance of a modern high-speed compressors. The two methods rely on a loss and deviation model capturing high negative incidences on the blading. The assumption of fully mixed wake employed in the low-order methods is verified by comparing the results from 2D RANS simulations of a single compressor stage in sub-idle conditions.

The low-order tools are used to generate the compressor characteristics in the locked-rotor and in the zero-torque windmilling case. The characteristics created are compared to 3D RANS simulations of subidle conditions run using ANSYS ${ }^{\circledR} \mathrm{CFX}^{\circledR}$. Both low-order tools match closely the results from CFD. The computational cost required by the mean-line tool is negligible even when creating a characteristic. The code ACRoSS requires approximately an hour to create a single characteristic. The 3D RANS CFD requires 6 hours for a single operating point on 64 CPU's.

The low-order tools presented in this paper represent an alternative to 3D CFD to generate the subidle conditions characteristics of a modern high-speed compressor. While these tools do not offer the same flow-field resolution as high-fidelity CFD, they have a similar accuracy in predicting performance. Therefore, they can be used to generate performance data useful in system models seeking to analyse the conditions of altitude re-lighting, cranking and starting, which are of great commercial interest. The analysis of the torque distribution highlighted the fact that, for the high hub-to-tip ratio machine analysed, torque variation is mostly uniform in the radial sense and varies mainly in the axial direction.

Thanks to the smaller computational cost and limited geometry input, these methods can be used to predict the sub-idle conditions performance of a compressor geometry during the early design stage, and can therefore support the development of a gas turbine for both the propulsion and power-generation applications. 


\section{ACKNOWLEDGEMENTS}

The authors would like to express their gratitude to Rolls-Royce plc. for funding this research and for permission to publish this paper. This research has been co-funded by Innovate UK. Special thanks to Mr. Richard Tunstall from Rolls-Royce plc. for supervising this work. This project was co-funded as well from the Clean Sky 2 Joint Undertaking under the European Union's Horizon 2020 research and innovation programme under grant agreement No 785349. Data subjet to third party restrictions.

\section{References}

[1] EASA Certification Memorandum: Turbine Engine Relighting In Flight, 2015, Pub. L. No. CS-E $910,1$.

[2] ZAChos, P. K. Modelling and analysis of turbofan engines under windmilling conditions, Journal of Propulsion and Power, 2013, 29, (4), pp 882-892.

[3] Walsh, P. P. and Fletcher, P. Gas turbine performance, John Wiley \& Sons, 2004.

[4] Riegler, C. and Bauer, M. and Kurzke, J. Some aspects of modelling compressor behavior in gas turbine performance calculations, ASME Turbo Expo 2000: Power for Land, Sea, and Air, 2000, pp $1-8$.

[5] KuRzKe, J. How to get component maps for aircraft gas turbine performance calculations, ASME 1996 International Gas Turbine and Aeroengine Congress and Exhibition, 1996, pp 1-7.

[6] Agrawal, R. K. and Yunis, M. A generalized mathematical model to estimate gas turbine starting characteristics, ASME 1981 International Gas Turbine Conference and Products Show, 1981, pp $1-8$.

[7] Gaudet, S. R. and Gauthier, J. E. D. A simple sub-idle component map extrapolation method, ASME Turbo Expo 2007: Power for Land, Sea, and Air, 2007, pp 29-37.

[8] Jones, G. and Pilidis, P. and Curnock, B. Compressor characteristics in gas turbine performance modelling, ASME Turbo Expo 2001: Power for Land, Sea, and Air, 2001, pp 1-7.

[9] Zachos, P. K. and Ruelke, C. and Pachidis, V. and Singh, R. Compressor Blade Modelling Under Highly Negative Incidence, ASME 2011 Turbo Expo: Turbine Technical Conference and Exposition, 2011, pp 431-441.

[10] Ferrer-Vidal, L. E. and Pachidis, V. and Tunstall, R. J. An enhanced compressor sub-idle map generation method, Proceedings of GPPS Forum 2018, Zurich, Switzerland, 2018.

[11] Righi, M. and PAchidis, V. and KöNözsy, L. Three-dimensional through-flow modelling of axial flow compressor rotating stall and surge, Aerospace Science and Technology, 2018, 7, pp 271-279.

[12] Longley, J. P. Calculating stall and surge transients,ASME Turbo Expo 2007: Power for Land, Sea, and Air, 2007, pp 125-136.

[13] Brand, M. L. An improved blade passage model for estimating off-design axial compressor performance, PhD Thesis, 2013, Massachusetts Institute of Technology.

[14] Aungier, R. H. Axial flow compressors: a strategy for aerodynamic design and analysis, ASME Press and Professional Engineering Publishing, 2003.

[15] Ferrer-Vidal, L. E. and Schneider, M. and Allegretti, A. and Pachidis, V., A Loss and Deflection Model for Compressor Blading at High Negative Incidence, Journal of Turbomachinery, 2019, 141, (12), pp 1-12. 
[16] Poinsot, T. J. and LeLE, S. K. Boundary conditions for direct simulations of compressible viscous flows, Journal of computational physics, 1992, 101, (1), pp 104-129.

[17] Veres, J. P. Axial and centrifugal compressor mean line flow analysis method, Nasa Technical Memorandum, NASA/TM-2009-215585, 2009.

[18] Sмiтн, S. L. One-dimensional mean line code technique to calculate stage-by-stage compressor characteristics, MSc Thesis, 1999, University of Tennessee - Knoxville.

[19] Binder, N. and Courty-Audren, S. and Duplaa, S. and Dufour, G. and Carbonneau, X. Theoretical Analysis of the Aerodynamics of Low-Speed Fans in Free and Load-Controlled Windmilling Operation, Journal of Turbomachinery, 2015, 137, (10), pp 1-12.

[20] Righi, M. and Ferrer-Vidal, L. E. and Allegretti, A. and Pachidis, V. Low-Order Models for the Calculation of Compressor Sub-idle Characteristics, $24^{T H}$ ISABE conference, Canberra, Australia, 2019. 


\title{
Body-force and mean-line models for
}

\section{the generation of axial compressor} sub-idle characteristics

\author{
Righi, Mauro
}

Cambridge University Press

Righi M, Ferrer-Vidal LE, Pachidis V. (2020) Body-force and mean-line models for the generation of axial compressor sub-idle characteristics. The Aeronautical Journal, Volume 124, Issue 1281, November 2020, pp. 1683-1701

https://doi.org/10.1017/aer.2020.58

Downloaded from Cranfield Library Services E-Repository 